\title{
الاساس القانوذي لعقد القرض العام
}

م.م / عذراء كاطلو هنـون

جامعة واسط / كلية القانوز

| الالفص باللغة العربية

يعرف عقد القرض العام على انهه مبلغ من المسال تحصل عليه الدولـة او احدى هيئاتها العامـة من

الاخرين على ان تتعهد الدولة برده مـع فوائده وفق الآجـال المتفق عليها. امـا من حيث طبيعته القانونية فقد اختلف الفقهاء فيما بينهم فبعضهم عده من عقود القانون العام الاداري، و البعض عده عمل من اعمال السيادة

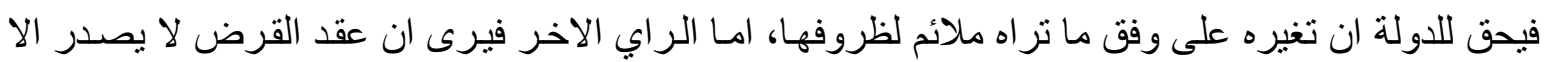
بقانون فانه لا يلغى الا بقانون اخر، ولأهمية عقد القرض اشترطت اغلب دساتير الدول ان يكون انعقاد عقد القرض من الاختصاص الحصري للسلطة التشريعية فلا يعقد عقد القرض دون مو افقة السلطة التشريعية . Summery

Public Loan is a an amount of money received by the state or its agencies from the individuals, in return, the state gave back the principal plus the interests rate agreed upon between them .

Scholars have not agree about the legal nature of the public loan, Some regarded it as an administrative contract while other consider it as a type of sovereign acts which enable the state to amend it according to her needs.

Other approach stipulate that Public Loan should be cancelled only by law because issue Public Loan come only by law.

Most Constitutions make Public Loan part of exclusive authority to legislature, no Public Loan can be issue without its approval

الاقدمة

تسعى الدول الى توفير حياة كريمة لشعبها وان يعيشو ا تحت ظل حكومتهم بأمن وامـان وطمأنينة لذا

نجد اغلب الحكومـات تتريث في اعداد موازنتها وتتخذ كل وسـائل الدقة و الحذر البعيدة عن الخيال في صياغتها لتحقيق اهدافها فـالمعلوم ان الموازنـة لا يمكن اعدادها الا بوجود عنصرين مهمين هما الاير ادات و النفقـات ويقصـد بـالإير ادات كل الامـوال التـي تحصـل عليهـا الدولـة مـن مصـادر ها المختلفـة (كالـدومين الضـرائب و الرسوم ـالاتـاوة ـالقروض ....). امـا النفقات العامـة فتعرف بانها تلك المبالغ المالية التي تقوم بصرفها الحكومة بقصد تحقيق منفعة عامة وإشباع حاجة عامة فيجب على الحكومة ان تقبد انفاقها ضمن مـا تتوقع ان تحصل عليه من الاير ادات ويمكن تحديد اوجـه الانفاق الحكومي بالمرتبات والاجور ـاثمـان السـلع و الخدمات ــ الاعانات بأنو اعها الدولية و الداخلية ـالقروض.

هنا نلاحظ ان القرض ذكر مرتان مرة باعتباره اير اد ومرة باعتبار انفاق وهذا مـا يميز القرض العام عن غيره من صور الاير ادات والنفقات، فيعد اير اد عند استلامه الا انه اير اد مؤقت يدخل الخزانة لأنه سوف يسجل بباب النفقات عند اعادة اصل القرض و الفوائد المتفق عليها، فهو ايراد استثنائي لا يجوز للحكومات 
اللجوء اليه الا عند الضرورة لمواجهة الظروف الاستثنائية بحيث لا تستطيع الحكومـة فرض ضر ائب جديدة لأنها بلغت حدها الاقصى او انها بلغت حجمها الامثل و اصبحت للضر ائب ردود فعل اجتماعية عنيفة وهذا يعني ان للضر ائب حدود اقتصادية واجتماعية تتقيد بها الحكومة (') ، ونظر الحاجة الدولة الى الاموال كبيرة لمو اجهة الكوارث والحروب والازمـات فأن الدولة تضطر الى عقد القرض العام (داخل اقليمها مـ الافراد و المصارف و المؤسسات الداخلية او خارج حدود اقليمها ) لان إير اداتها الاعتياديـة لا تسمح لها بسداد الانفاق الاستثنائي.

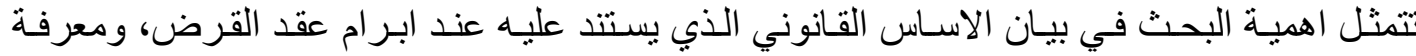
الطبيعة القانونية للعقد وبيان موقف الدستور العر اقي من عقد القرض .

خطة البمث:-

سوف نقسم البحث الى اربع مباحث نتناول في الاول منه ماهية عقد القرض العام امـا في المبحث الثاني الطبيعة القانونية لعقد القرض العام واخير ا نبين في المبحث الثالث طرق انقضـاء عقد القرض العام وحسب التفصيل الاتي .

\section{المبمث الاول / ماهية مقد القرض العام}

هنا نقسم المبحث الى مطلبين نتنـاول في الاول تعريف القرض العام وبيان خصائصسه التي تميزه

عن غيره من المصطلحات المالية الاخرى وفي المطلب الثاني نبين انو اع القرض وحسب التفصيل الاتي:-

\section{الإhب الاول / تمريف القرض المام}

يعرف القرض العام على انه مبلخ نقدي تستوفيه الدولة اواي شخص معنوي اخر من الغير (سواء كان الغير افراد او بنوك او الهيئات الخاصـة ام الدولية او دولة اخرى ) وتتعهد برده ويدفع الفائدة عنه وفقا

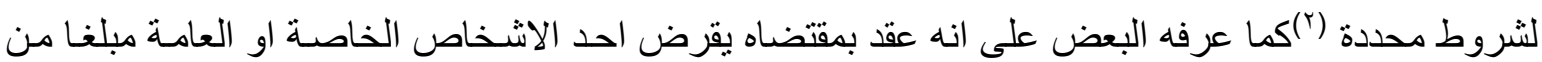
المـال الى الدولة او الى شخص من اشخاص القانون العام مقابل تعهدها او تعهده بدفع فائدة سنوية محددة ويـرد القـرض في نهايـة الاجـل المحدد (־) في حين ان قـانون الادارة الماليـة والدين العـام العراقي عرف

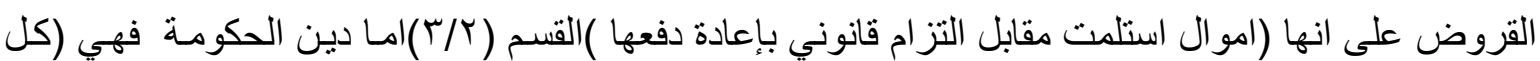
ديون الحكومة والتي يتطلب دفعها او دفع فو ائدها واصولها من المقترض الى المقرض في تاريخ او تواريخ

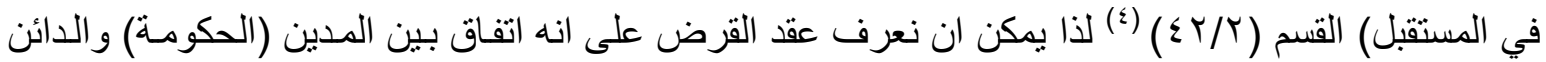

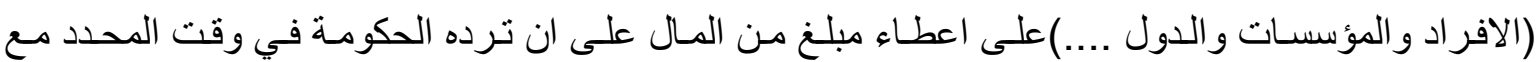
الفو ائد المتفق عليها.

من خلال التعاريف السابقة يتضح لنا ان لعقد القرض العام خصائص معينة يمكن اجمالها بالاتي(0) 1 - عقد القرض مبلغ من المال:-قد يكون المال عينـا او نقدا والصفة النقديـة هي الغالبة في الحاضـر كمـا يمكن الاكتتـاب بـالقرض العـام عينـا بموجب اسـناد دين عـام قديم بحيث يتم بصـورة استبدال قرض جديد بالقرض القيم 


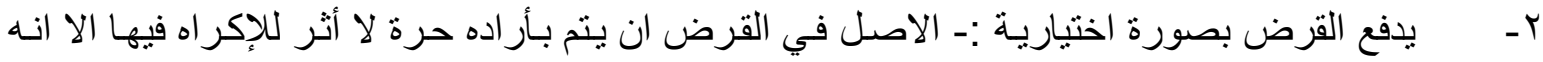
يحق للدولـة ان تفرض قرضـا اجباريـا عندما تواجـه ازمـات اقتصـادية وماليـة خطرة او عندما تواجهه عدوان خارجي.

r- يدفع القرض العام من قبل احد اشخاص القانون العـام او الخاص سواء يتمتعون بجنسيتها ام اجانب كما تلجأ احيانا الى الدول الاجنبية و المؤسسات المالية الوطنية والدولية طلبا للمال. ـ - القرض يدفع للاولة او الاشخاص العامـة الاخرى سواء كان الثخص هو سلطة مركزيـة ام وحدات ادارية محلية ام هيئات عامة تتمتع بشخصية اعتبارية وباستقلال مادي و اداري. ــ يتم القرض العام بعقد بين الدولة او الهيئات او المؤسسـات العامـة التي تتعهد برد مبلغ القرض مـع الفوائد السنوية والطرف الثاني هو الدائن الذي يتعهد بإقراض مبلغ من المال الى الطرف الاول. 7ـ - يستند القرض العام الى موافقة البرلمان وذلك لكونه يؤدي الى تحميل الدولـة التزامـات ماليـة وشروط مرهقة للحكومة لذا نجد ان اغلب الدساتير نصت على شرط مو افقة البرلمان قبل عقد القرض ـ .

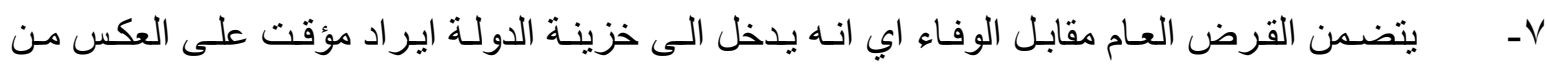
الضـريية التي توصف بأنها مورد نهائي دون مقابل حيث تتعهد الدولـة في عقد القرض برد اصل المبلغ و الفو ائد المترتبة على القرض الى الدائن خلال مدة متفق عليها سابقا .

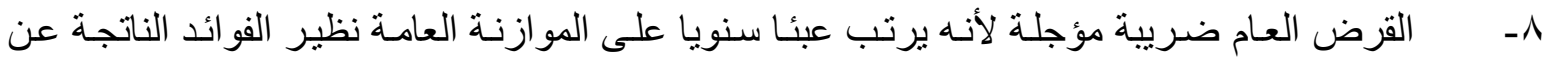
مبلغ القرض فعند ابرام العقد يسجل على انه ايراد ولكن عند الوفاء بـه يدخل ضـمن الانفاق لذا يطلق عليه ضريبة مؤجلة فهو ضريبة عن ايراد سابق يتحمل اعباءه في المستقبل .

\section{المطاب الثاني / انواع القرض العام}

تقسم القروض العامـة الى عدة انواع حسب معيار التقسيم فمن حيث مصدر ها المكاني تقسم الى قروض داخلية وقروض خارجية ،اما من حيث المدة فتقسم الى قروض مؤبدة وقروض مؤقتـة (طويلـة الاجل وقروض متوسطة الاجـل وقروض قصـيرة الاجلـ)، امـا عن معيـار الحريـة فتقسم القروض الـى قروض اختيارية وقروض اجبارية لذا ارتنئنا ان نقسم المطلب ال ثلاث فروع وحسب التقسيم الاتي:-

الفرع الاول / معيار المكان:-

من حيث المصدر المكاني يمكن ان نقسم القرض الى قروض داخلية وقروض خارجية. فالقروض الداخلية هي القروض التي يكتتب بها الاشخاص الطبيعيون او الاعتباريون داخل الدولة المقترضة ويستلزم في عقد القرض الداخلي تو افر عدة شروط منها 1 - ضرورة توجيه هذه القروض لتمويل السياسة الانمائية للدولة .

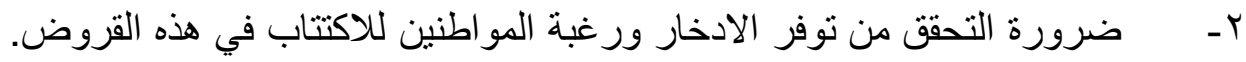

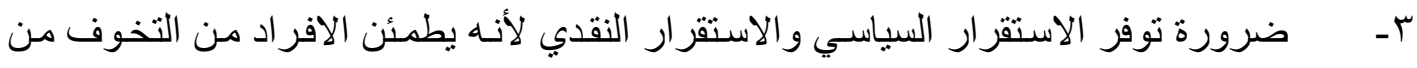

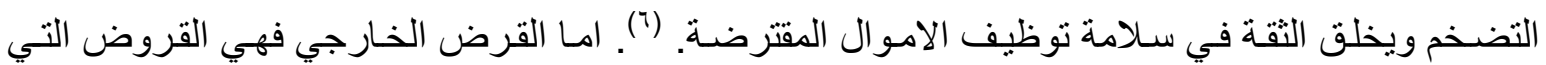
تحصل عليها الدولة من مؤسسـات او منظمات مالية اجنبية او من حكومات ودول لها القدرة في منح الدولة 
المقترضة مبالغ من المال او امو ال عينية مقابل ان تقوم الدولة المقترضـة بسداد قيمـة القرض وفو ائده ضـمن المدة المحددة (ºثل القروض التي يمنحها صندوق النقد الدولي و البنك الدولي للتنمية والتعمير .....

\section{الفرع الثاني / هعيار الوقت:-}

هنـا قد تكون القروض مؤبدة او مؤقتـة (القصيرة المدة او الطويلـة المدة و المتوسطة المدة)،يقصد بـالقروض المؤبدة القروض التـي لا تحدد الدولـة تاريخـا معينـا لردهـا وانمـا تلتززم بدفع الفائدة عنهـا مادامت قائمـة(^)، وتسنطيع الدولة تسديدها في الوقت المناسب لها ، وينسب للقروض الدائمسة عدة مز ايـا فهي تترك للاولة حرية تحديد الوفاء، ومن ثم تقوم بتسديدها في الوقت الذي تثـعر بقدرتها على التسديد كذلك فإن عبء القرض المؤبد يخف مع الزمن ، نتيجة انخفاض القوة الثـر ائية للنقود أو نتيجة لازدياد الثروة العامـة بمـا فيها موارد الدولة (9) ،و هذا خلاف القروض الموقتة التي يقصد بها القروض التي تتعهد الدولنة فيها بالوفاء عند تاريخ معين ويمكن تقسيم القروض من حيث أجل سدادها إلى ثلاثنة : قروض قصيرة الأجل ، وقروض به متوسطة الأجل ، وقروض طويلة الأجل . فأما القروض القصبرة الأجل فإن مدتها لا تتجاوز السنتين، ويطلق عليه القروض السـائرة أو العائمـة ، وتسمى السندات التي تصدر بها هذه القروض أذونـات الخزانـة، و التي تصدر ها الحكومة لتتمكن من الحصول على أموال بصفة عاجلة لتغطية العجز المؤقت في الموازنـة العامـة ولا

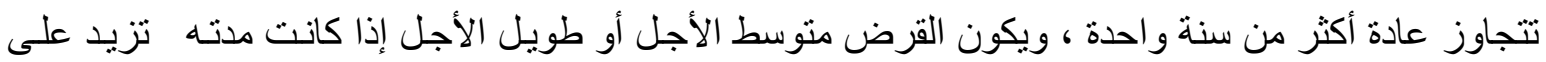

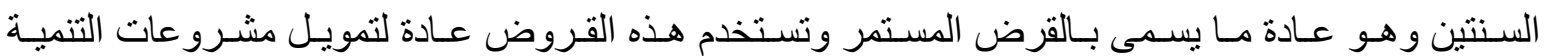
الاقتصادية أو نفقات المجهود الحربي او الأزمات الاقتصـادية ، أخيراً فإن البرلمانات غالباً مـا تعطي أهمية أكبر إلى القروض متوسطة الأجل وطويلة الأجل أكثر من القروض قصيرة الأجل و إن القروض متوسطة

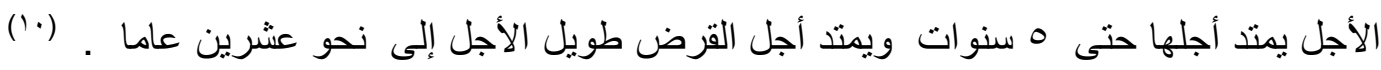

\section{الفرع الثالث / من هيش هرية الاكتتاب :-}

الاصل بالقرض انه عقد اختياري اب ان الافر اد احرار بالاكتتاب بـالقرض الا انه ممكن ان يجبر الغير على الاكتتاب بالقرض وهو ما يعرف بالقرض الاجباري ،ويمكن تعريفه بأنه القرض الذبي تلجأ الدولة اليه عندما تضعف ثقة المو اطنين بها بسبب الازمات الاقتصادية وارتفاع مستوى الاسعار وتدهور قيمـة النقود حيث تلجـأ الدولـة للقروض من اجل امتصـاص اكبر قدر من كميـة النقود والحد من اثار التضخم، ('") امـا القرض الاختياري فهو القرض الذي تحصل عليه الدولة طو اعية واختبار ا حيث تقوم الحكومة بتحديد شروط العقد وتفاصسيله دون مباشـرة أي نوع من انواع الضغط و الاكر اه على الافر اد حيث تدفعهم المزايـا الماديـة

و المعنوية للإقبال عليه. (r)

\section{المطب الثالث/ شروط عقد القرض العام}

هنالك مجموعة من الثروط يجب تو افر ها لإصدار القرض منها تتعلق بمبلغ القرض فقد يكون محدد منذ البداية وقد لا يتحدد ، وشكل السندات فقد تكون سندات اسمية وقد تكون لحاملها و السندات المختلطة ، وسعر اصدار القرض اضافة الى المزايا الممنوحة للمكتتبين وحسب التفصيل الاتي:- 
يعد تحديد مبلغ القرض العام من المر احل الاولى التي يتعين على الدولة تنظيمها يمكن ان يصدر

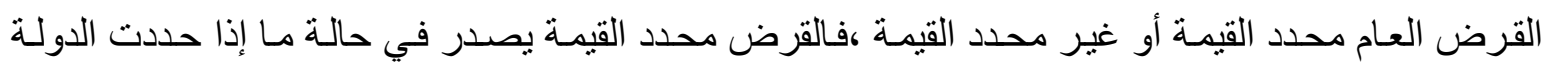
مسبقا حدا أعلى للمبلغ اما القرض غير محدد القيمة فيصدر في حالة مـا إذا لم تحدد الدولة أو الجهة الإداريـة المقترضة مبلغا لذلك و انما تقوم الدولة بتحديد تاريخ معين ينتهي الاكتتاب بنهايته وبذلك فان مقدار القرض يتحدد بحلول هذا التاريخ وغالبا ما تلجأ إليه الدولة لهذا النوع في الحالات التي تحتاج فيها إلى الحصـول على التى مبالغ كبيرة لتغطية أزمـة أو كارثة مثل أوقات الحروب و الكوارث. (r'ا') فمن الناحية القانونية نجد ان تحديد مبلغ القرض من اختصاص السلطة التنفيذية .

\section{الفرع الثانبي /شكل السندات :-}

تتخذ القروض العامة شكل سندات حكومية تصدر ها الدولة وتطرحها للتداول حيث يمكن ان تصدر سندات القرض العام بثلاث اشكال منها السندات الاسمية التي يقيد فيها اسم مالكها في سجل خاص للدين يحفظ في ادارة القروض العامة بوز ارة المالية وتسلم اليه شهادة باسمه تتبت حقه تجاه الدولة ويترتب على ذللك ان انتقال ملكيتها يتطلب تعديل البيانات الواردة في الثـهادة والسجل واحلال اسم المالك الجديد محل اسم المالك القديم وبدون هذه الاجر اءات فلا يعتد بنقل ملكيتها قبل الدولة باعتبار هـا المدين بقيمة السند ومن فو ائد هذه السندات انها لا تدفع الا باسم الثابت فيها او من ينوب عنه قانونـا وهي بذللك تمثنل حمايـة لمالكها ضـ خطر

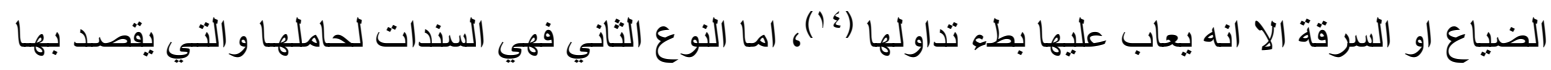

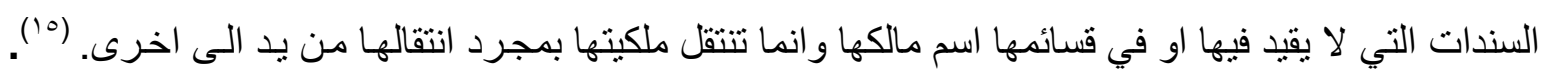
اما النوع الثالث فهي السندات المختلطة وهي وسط بين النوعين السابقين فتكون اسمية بالنسبة للمبلغ المكتتب فيه وتكون لحاملها بالنسبة لتحصيل الفو ائد حيث يلحق بهذا النوع من السندات قسائم خاصة بالفائدة. (17)

\section{الفرع الثالث /سعر الاصدار :-}

من شروط عقد القرض العام هو ان يأخذ بأحد السعرين امـا بسعر التكافؤ او بأقل من سـر التكافؤ فاذا اصدرت الدولة القرض بنفس القيمة يقال أن القرض قد صدر بسعر التكافؤ اما اذا اصدرنه بسعر اقل من بن بأن تللك القيمة قيل ان القرض صدر باقل من سعر التكافؤ اي ان المكتبب يدفع اقل من مبلغ الاكتتاب وعند تسديد دين القرض يتسلم المبلغ كاملا ويطلق على هذا الفرق مكافأة التسديد او جائزة السداد والهدف منها هو تحفيز الافر اد على الاكتتاب في القرض ويفضل الاصدار بسعر التكافؤ اذا كانت الاموال المتطلب الاكتتاب بها منوفرة بالأسواق المالية بحيث يمكن تغطية القرض بسهولة حتى لو كان المبلغ كبير آما اذا خشيت الدولة قلة

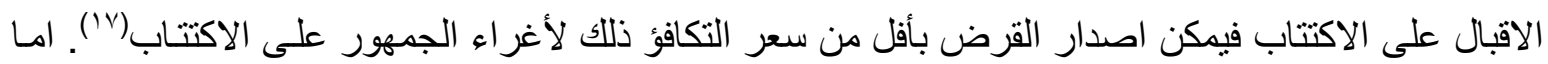

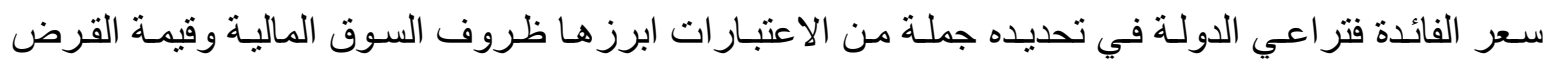

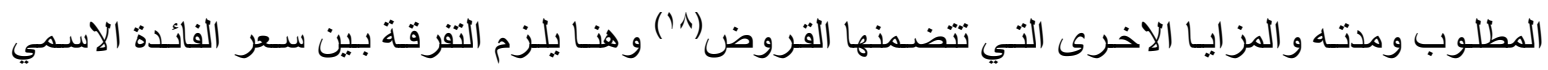
و السعر الحقيقي حيث يمكن تعريف سعر الفائدة الاسمي بأنه المبلغ الذي يدفع سنويا او نصف سنوي حسب الاحوال عن كل جزء من القرض امـاسعر الفائدة الحقيقي فيختلف بحسب مـا اذا كان اصدار القرض قد تم 
بسعر التكافؤ او بسعر اقل من التكافؤ او بجائزة السداد وتحدد الدولة مو اعيد دفع الفوائد وقد جرى العمل على

ان تدفع الفو ائد سنويا. (9)

\section{الفرع الرابع / المزايا والضمانات:-}

تمنح الدولة في سبيل ترغيب الغير(الافر اد و المؤسسـات والدول...) في عملية الاكتتاب جملة من

المز ايا والضمانات منها مكافأة السداد -جو ائز اليانصيب ـالاعفاء من الضرائب ـعدم الحجز على السندات

ـتأمين المكتتبين من خطر انخفاض قيمة النقود.

فيقصد بمكافأة السداد هو اعطاء الدولة مبلغ اضـافي على قيمة السند الاسمي عند تسديده وبالحقيقة ان مكافأة السداد لا تختلف من حيث نتيجتها عن الاصدار بأقل من سعر التعادل فكلاهما يلزم الدولة بمبلغ من المال يزيد عن المبلغ الذي اقترضته فهما يثتركان بالمزايـا والعيوب.، امـا جوائز اليانصيب فتقرر الدولنة اجر اء سحب سنوي للسندات واعطاء الفائزة منها جائزة مالية تكون ضخمة في الغالب غير ان هذه الطريقة منتقدة لأنها لا تتجح في جذب كبار المقرضين الذين يفضلون الحصول على فائدة مرتفعة مضمونة بدلا من الحصول على فائدة منخفضة وجائزة كبيرة غير مؤكدة ، اما عن الاعفاء من الضر ائب فتتضمن هذه المزيـة اعفاء السندات او فو ائدها او كلاهما من جميع الضـر ائب او من بعضـها سواء كانت ضـر ائب مفروضـة في الحال او التي ستفرض في المستقبل رغم ما لهذه المزيـة من تشجيع الغير على شر اء هذه السندات الا انها منتقدة من عدة نواحي فتقريره مخالف لمبدأ عمومية الضريبة على الاموال كما انه يفوت على الدولة حصيلة ضريبة تزداد ضخامة كلما ازداد حجم الدين العام كما انها تفتح بـاب للتهرب اذ يبرز بعض المـولين للسلطة المالية سندات لحامله استعارو ها من غير هم على انها جزء من ثروتهم فيتمتعون بالإعفاء عنها. (·.) ومن ضمن المزايـا الاخرى التي تمنحها للاولتة للغير هو التأمين ضد خطر انخفاض فيمـة النقود فتستطيع الدولة تلافي هذا الخطر عندما تلجأ الى تقرير سعر فائدة مرتفع جدا يعوض مـا يتحمل ان بطر أ من انخفاض في قيمة النقود وما يترتب عليه من رد المبالغ المقترضة بقيمة اقل من قيمتها الحقيقية عند الاقر اض الا ان ما يعيب هذا الضمان انها تؤدي الى عبء مالي ضخم يقع على الخزانة العامـة للدولة وهي تسدد خدمـة الدين العام فضلا عن كونها تتضمن اعتر افا من جانب الدولة بأن نقدها ينخفض مرة اخرى خلال مدة القرض كما قد تلجا الدولة الى ربط قيمة القرض الحقيقية بمال عيني حيث يرتفع قيمة الاخير بارتفاع المستوى العام للأسعار، ويمكن للاولة ان تختار هذا المال العيني لتأمين المقرضين منها ربط القرض العام بالذهب فتلتزم الدولة برد المبلغ الاصلي للقرض على اسـاس قيمته بالنسبة للذهب عند سداد القرض بشرط ان يكون اتجاه الذهب اللى الصعود دون الهبوط و عند انخفاضه يسدد القرض على اسـاس القيمة الاسمية لسندات القرض. او ربط القرض بـالعملات الاجنبيـة (سعر الصرف) فهنـا على الدولة ان تختار احدى العملات الاجنبيـة الثابتـة نسبيا فترد القرض على اساس قيمة هذه العملة تجنبا لما قد يطر أ على قيمـة العملة الوطنية من انخفاض، كما يمكن للاولـة ان تربط القرض بالأرقـام القياسية لأسـعار بعض الســع (المسـتوى العـام للأسـعار ) ويعد هذا

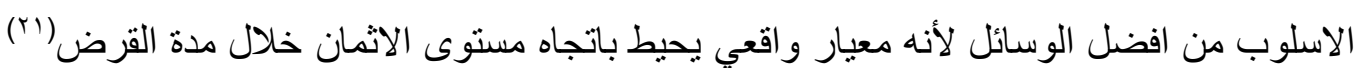




\section{المطاب الرابع / طرق اصدار القرض}

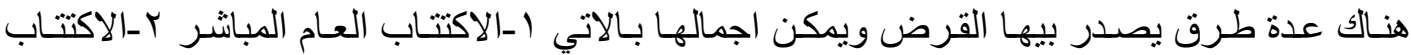
المصرفي بـ الاكتتاب بالبورصة عـ الاكتتاب بالمز ايدة لذا سوف نقسم المطلب الى فوع وكما يأتي :

الفرع الاول/ الاكتتاب العام المباشر:-

تتـولى الدولـة بنفسـها بطرح سـندات القرض العـام مباشـرة مـع مـن بريـد الاكتتـاب مـن الاشـخاص الطبيعيين و الاعتباريين محددة بدء ميعاد الاكتتاب ونهايته وشرط القرض و المز ايا التي تمنح للمكتببين فيه وتتميز هذه الطريقة بأنها توفر على الدولة المبالغ التي تحصل عليها البنوك في حالة اصدار القرض عن طريق البيع للبنوك كما تمتاز بتمكين الدولة من بسط سيطرتها على عمليات الاصدار ومنع عمليات المضساربة على سندات القرض الا ان ما يعيبها خطر عدم تغطية القرض بأكمله ممـا قد ينـال من الثقة المالية للدولة الى لى حد كبير وقد تكون الدولة غير ملمة بأحوال السوق المـالي و النقدي عكس البنوك و المؤسسـات المالية الاخرى وبالتالي تكون هذه الاخيرة اكفأ في طرح السندات ونتجيع الافر اد على القبول بها دون معوقات القرض

\section{الفرع الثاني /الاكتتاب المصرف:-}

هنـا تقوم الدولـة بييع سـندات القرض للمصـارف بسـعر اقل مـن قيمتهـا الاسـية وبعد ذلك يتولى المصرف بيع هذه السندات للجمهور بالقيمة الاسمية مقابل عمولة تحصل عليها تمثل في الفرق بين المبلغ

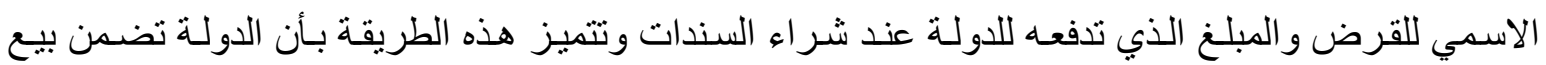
جميع الســدات وحصـولها على قيمـة القرض بأكملـه دون ان يتعـرض مركزهـا المـالي للخطر الا ان لهـذه الطريقة عيوب فهي تحرم خزينة الدولة من جزء من الاموال و الذبي يتمثل في الفرق بين المبلغ الاسمي للقرض و المبلغ الذي تدفعه المصارف فعلا للدولة (rr)

الفرع الثالث /البيع في البورصة:-

هنا تقوم الحكومة بطرح السندات في البورصـة للاكتتاب فيها اب اخضـاعها لقوى السوق الحاكمـة للبورصة ،وهنا قد يزيد الطلب عليها كما قد لا تلقى اقبالا وفي هذه الحالة ينخفض ثمنها ممـا يعني ارتفاع سعر الفائدة مما يحمل الموازنـة اعباء مالية لا تتناسب مـع مـا حصلت من مبالغ نقدية وقد لا يتم شر اء كل

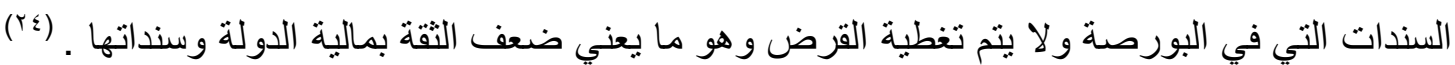

\section{الفرع اللرابع /الاكتتاب بالمزايدة :-}

هنا تعرض الدولة سندات القرض للمز ايدة مع الجمهور او البنوك و المؤسسـات المالية الاخرى بعد ان تحدد سعر ادنى للقرض وفي هذه الحالة قد تقبل الدولة الاكتتاب في سندات القرض بسعر دون سـر التعادل او بأعلى من سعر التعادل و اكثرها قربا من سعر التعادل حيث تعمل الدولـة على تخصيص السندات

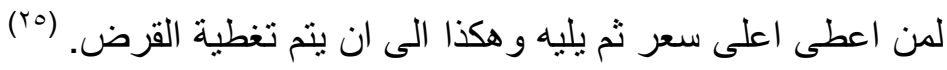




\section{المبمث الثاني / الطبيعة القانونية لعقد القرض العام}

اتفق الفقهاء على ان عقد القرض من عقود القانون العام ويخضع لجميع قو اعده و احكامسه التي تسري على الغير فهو عقد ملزم لطرفيه يرتب حقوقا للمقرض (الدائن) و التزامـا على المقرض(المدين) ، و لا يجوز

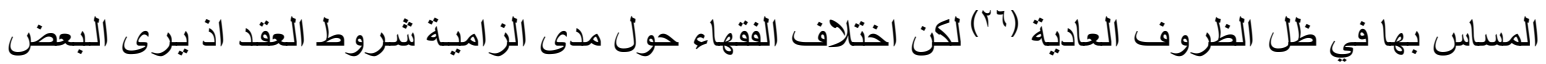
ان القرض يصدر بقانون فلا يغيره او ينهيه الا قانون اخر ،ويرى رأي اخر على أن القرض عمل من اعمـال السيادة ومن ثم يمكن الدولة التجاوز على شروط العقد او بعضها ، اما الر أي الثالث فيرى ان عقد القرض لـ لـه له صفة الزامية ومن ثم يجب عدم تعديلها من جانب واحد، وان صدر قانون يعدل او يلغي قرض عام لا يعني الغاء التز ام الدولة حيث تظل مدينـة للمقرض(rV) وان اشتر اط اصدار القرض بقانون ليس لله من القانون الا الثكل لانه لا يعني اكثر من الاذن للحكومة بعقد القرض استنادا لاختصاصساتها المالية (^^ميث يقتصر هذا

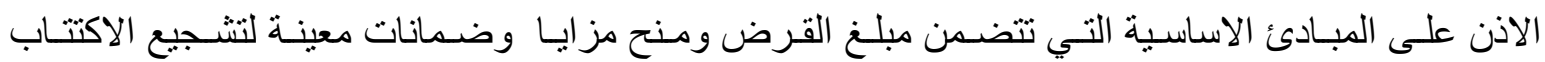
بسندات القرض اما طرق الاصدار وسعر الفائدة والمزايا الاخرى الممنوحة للمكتتبين فيترك تحديدها للسلطة التنفيذية (9) لذا نجد اغلب الدساتير نصت على ضرورة موافقة ممثلي الثعب على عقد القرض كالدستور

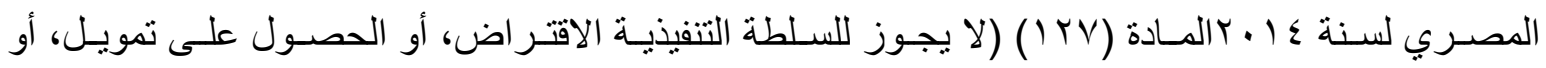
الارتباط بمشروع غير مدرج في الموازنة العامة المعتمدة يترتب عليه إنفاق مبالغ من الخزانة العامـة للدولة

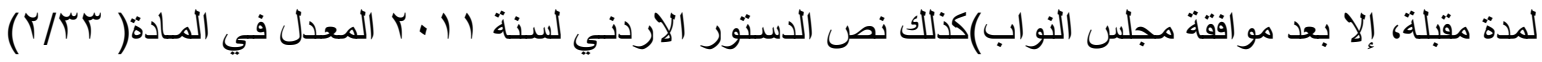
(المعاهدات والاتفاقات التي يترتب عليها تحميل خزانة الدولة شيئاً من النفقات او مساس في حقوق الاردنيين العامة او الخاصة لا تكون نافذة الا اذا وافق عليها مجلس الامة.... ) اما في العراق فأن الدستور النافذ لسنة

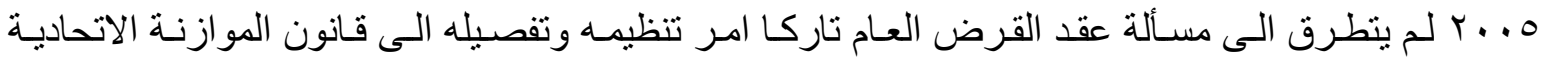
وقانون الادارة المالية والدين العام وفقا للإجر اءات المستقرة فيهما الا انه اثشار الى ان القرض من اختصساص السلطة الاتحادية حيث نصت المادة ( • (1) منه ( تختص السلطات الاتحادية بالاختصاصات الحصرية الآتية: او لاً :-ـرسـم السياســة الخارجيـة و التمثيـل الدبلوماسـي، و التفـاوض بثــأن المعاهـدات و الاتفاقيـات الدوليـة، وسياسات الاقتر اض و التوقيع عليها وابر امها، ورسم السياسـة الاقتصـادية والتجاريـة الخارجية السيادية....).

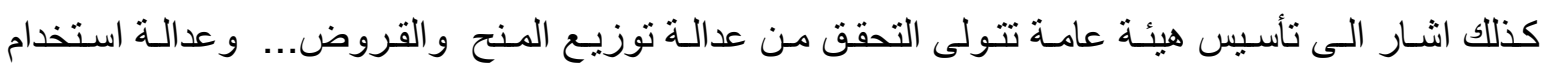

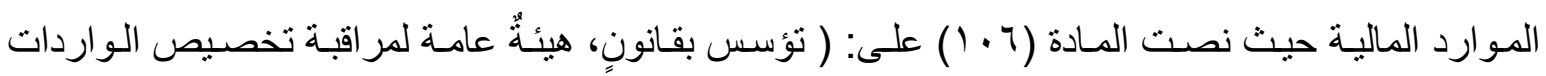

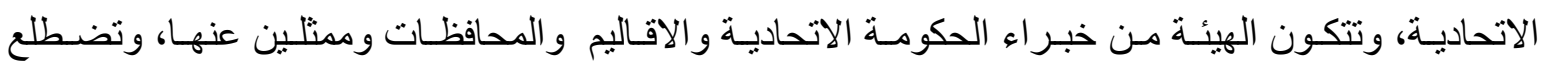
بالمسؤوليات الآتية: اولاً :- التحقق من عدالة توزيع المنح والمسـاعدات والقروض الدولية، بموجب استحقاق الاقاليم والمحافظسات غير المنتظمة في اقليم.

ثانياً :- التحقق من الاستخدام الامثل للموارد المالية الاتحادية و اقتسامها.) اما قانون الادارة المالية و الدين العام رقم 90 لسنة ؟ . . بالجمهوريـة العراق فقد نظم القسم العانشر

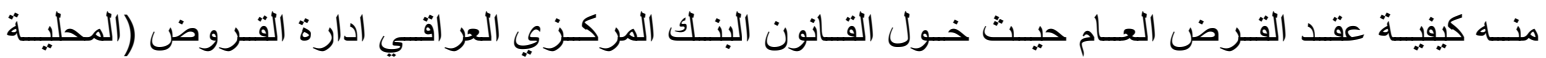


و الخارجية...) و اعطى صلاحية للمحافظات و الحكومات الاقليمية الحصول على القرض و اصدار الضمانات بعد ابـلاغ وزير المالية وضمن الحدود المصـادق عليها من مجلس الوزراء بنـاء على توصية وزير المالية

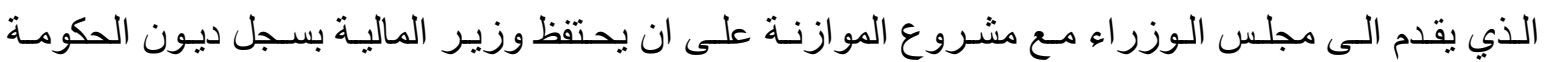
الفدر الية كما ان من مهام وزير المالية توقيع عقد القرض و الضمانات المتعلقة بالحكومـة الفدر اليـة والتعاقد مـع البنلك المركزي العر اقي للحصـول على الخدمات المطلوبـة كذللك اكد القسـَ / ب مـن قـانون الادارة الماليـة العر اقية على حصر نوقيع عقد القرض لوزير المالية نظر الأهمية القروض حيث نص (لوزير المالية ان يفوض الصلاحيات الممنوحة لله بموجب هذا الامر الى موظفو وزارة المالية المخولين ، باسنتثاء التنازل عن حق الحكومـة الفذر اليـة بجمـع المبـالغ التي تملكهـا ، وتقديم مشـروع الموازنــة الفدر اليـة السـوية الـى مجلس الوزراء وتوقيع القروض و عقود ضمان الحكومة الفدراليـة). وبالنهايـة يمكن القول بـان عقد القرض العام هو عقد اداري يقرض بمقتضاه احد اشخاص القانون الخاص فردا كان او شركة مبلغـا من المـال للاولة او لاحد

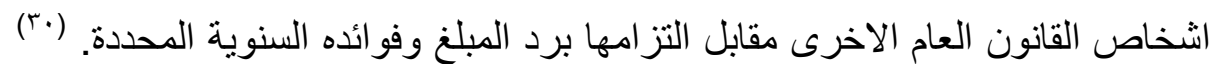
و عد عقد القرض عقدا اداريا وذللك لاحتو ائه على شروط واحكام خاصة يمكن اجمالها بالاتي:-

1- ان تكون الادارة طرفا في العقد. r- ان يتصل العقد بمرفق عام من حيث تنظيمه او تسييره او ادارته او استخلاله . r- ان تتجه نية المتعاقدين عند ابر ام العقد الى الاخذ بأساليب القانون العام .

اي انه تضمن شروطا استثنائية غير مألوفة في عقود القانون الخاص . ('"م) ، والجدير بالذكر ان عقد القرض لا ينعقد الا بعد الحصول على موافقة من السلطة التشريعية وذلك لخطورة عقد القرض ومـا يرتبـه من تبعات سياسية و اقتصـادية ومالية واجتماعية على الدولة المقترضـة لان مبلغ القرض سيكون عبئ على

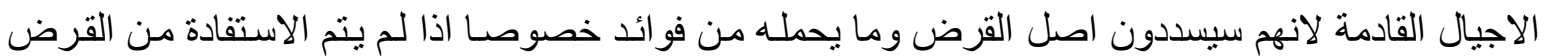
بصورة صحيحة ،لذا على البرلمان ان يدرس الاسباب التي تدعوا الحكومـة الى ابرام عقد القرض والوقوف

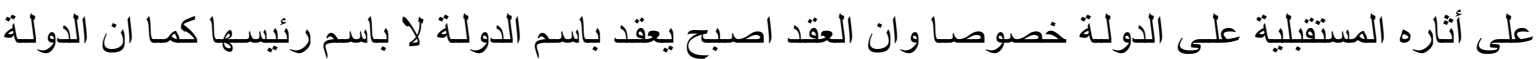
تقدم مو اردها كضمان لتسديد ديونها و الفو ائد المترتبة عليها لذا على الدولة ان تستخدم القرض في المشـاريع الاستثمارية ذات الانتاجية العالية والمعدة للتصدير مما يؤدي الى توفير فرص العمل وزيـادة الصـادرات ومن ثم الحصول على العملة الصعبة التي يمكن استخدامها لسداد الدين العام فالقرض وإن اختلفت صوره و وانواعـه، فانه يعد احد الوسـائل لسـد عجز الموازنـة وحاجة الدولـة للأمو ال لذا يشترط في ابرامـه الحصول على اذن

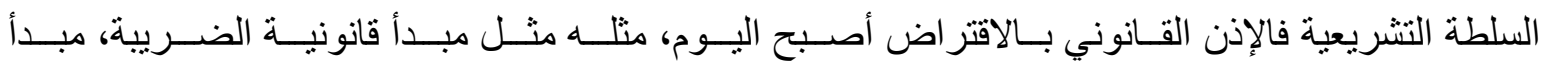

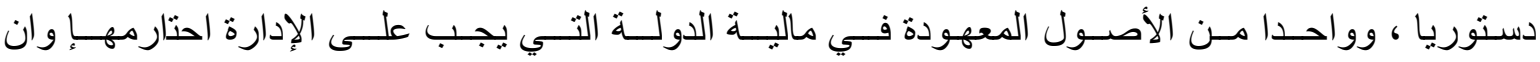

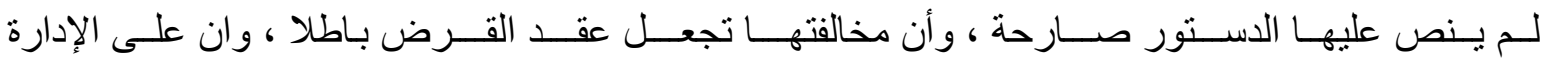

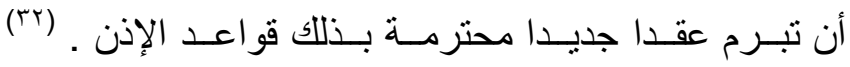
هذا ويكمن الاساس القانوني في اجازة البرلمان لعقد القرض للأسباب الاتية :ا ـ كونه يؤدي الى تحميل الدولة التزامات مالية وشروط قد تكون مرهقة اوفي غير صـالح الحكومـة لذللك فأن القاعدة المسلم بها في معظم الدول ضرورة موافقة البرلمان على القروض العامة وان يصدر بقانون . (Trآ 
r- كذلك يرجع اشتراط مو افقة السلطة التشريعية على اساس حقها في فرض الضر ائب لأنه لو أجيز للسلطة التنفيذية الالتجاء الى الاقتر اض دون موافقتها لعمدت السلطة التنفيذيـة الى عقد القرض في كل حالة يرفض

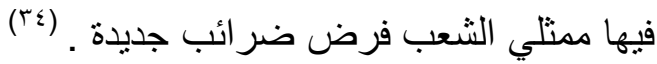
rـ ان اشتر اط موافقة البرلمان على اصدار القرض العام يعد خير وسيلة للإعلان عنه ولفت نظر الراي العام اليه مما يساعد على نجاح الاكتتاب به .. (º) ويعد احد الوسائل لمناقثة بنود العقد وكيفية استثماره. ع - كما يهيئ الفرصـة للسلطة التشريعية معرفة اوجـه انفاق القرض وممارسـة سلطة الرقابـة كذلك ان شرط

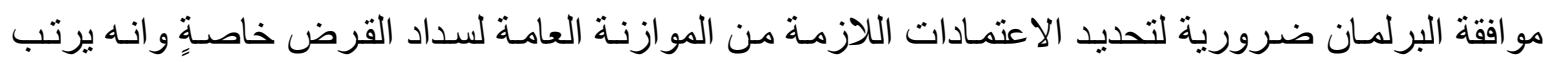
التزامـات ماليـة مستقبلية على الدولة لذا يشترط ان لا يكون مقرون بشروط تمس بسيادة الدولة من الناحيـة

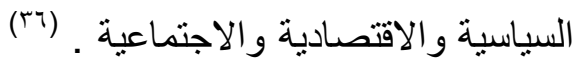
هـ كما ان مناقتشة القرض العام من قبل السلطة التشريعية يهيئ لها معرفة اسباب ومبرر ات القرض مما يزيد

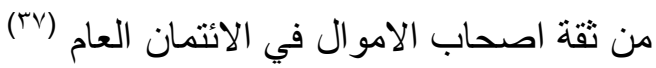
المبمث الثالث/ انقضاء عقد القرض يقصــ بانقضـاء القرض العـام التخلص مـن العببء المـالي للقرض العـام اب انقضــاء اصـل الدين و الفو ائد المترتبة على الدين، وينتهي القرض العام امـا بالوفاء بـه او باستهلاكه او بأنكاره او بتبديله وحسب الب التفصيل الاتي:-

\section{الامطب الاول / الوفناء بالقرض العام}

يتم الوفـاء بـالقرض بحلول الاجل المحدد وهو الطريق الطبيعي للوفـاء باللديون الا انه قد يصسب سدادها مرة واحدة بالنسبة للقروض الكبيرة و الطويلـة الاجل لذا نلاحظ ان الوفـاء لا يحدث الا للقروض قصيرة الاجل وصغيرة الحجم اما القروض الطويلة الاجل والكبيرة فيتم انقضاءها باستهلاكها. (^ז)

\section{الاكلبب الثاني /استهلاك القرض}

يقصد باستهلاك القرض العام سعي الدولة للتحرر منهه نهائيا برد قيمته على شكل دفعـات مثتاليـة خلال فترة معينة تتص عليها شروط اصدار القرض ،الا ان استهلاك القرض العام بتطلب تو افر الاموال حتى هي تسنطيع الدولة دفع قيمة السندات لأصحابها وتختلف طرق تدبير الاموال بـاختلاف الظروف التي تمر بها كل

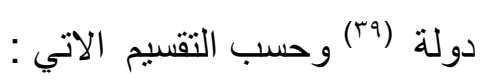

\section{الفرع الاول / طرق استهلاك القرض :-}

هنالك عدة وسائل لتحديد طرق استهلاك القرض منها

او لا / استهلاك القرض على شكل اقساط سنوية يعد من اكثر الاساليب الفنية استخداما حيث تدفع الدولـة سنويا

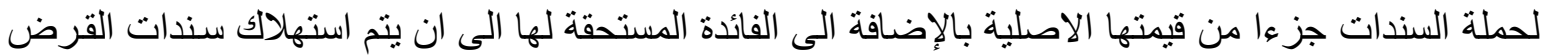
بأكمله ويعيب اسلوب الاستهلاك انه يجزئ في عملية دفع السندات لأصحاب الحق فيها وقد تكون قيمتها قليلة بحيث لا تحقق ميزة للدائنين او اصحاب رؤوس الامو ال الذين يفضلون عادة امسا بقاؤهم دائنين بمبلغ كبير يستحقون عنه فوائد سنوية او يستردون ديونهم كاملة لاستغلالها في وجوه اخرى لذللك الدولـة لا تلجـأ الى لى 
استهلاك قروضها عن هذا الطريق الا مـع المؤسسات المالية العامـة او شركات التأمين حيث لا تضـار هذه

المؤسسات و الشركات من استرداد قيمة القرض على اقساط سنوية خلال مدة معينة. (•؛) ثانيا/ التسديد بطريق القرعة: بموجب هذه الطريقة ترصد الدولة مبلغـا سنويا لتسديد جزء من الدين العام وتجري قرعة بين سندات القرض وتسدد تلك السندات التي تقع القرعة عليها. تمتاز هذه الطريقة بـان قيمة السند يسدد بأكمله الا ان ما يعيبها اضر ار ها بالأفراد حين تكون اسعار السندات في سوق الاوراق الماليـة اكبر من اسعار ها الاسمية لان الدولـة تسدد بالسعر الاسمي كذلك هذه الطريقة تضـر بالدولـة في حالـة انخفاض

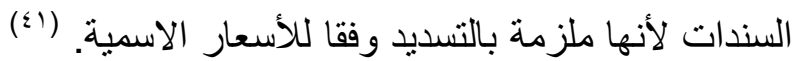

ثالثا/ استهلاك عن طريق الثراء من البورصـة. وفقا لهذه الطريقة تلجأ الحكومة الى سوق البورصـة المالية لتشتري منها كمية من سندات القرض عندما يكون سعر السندات في البورصة دون سعر التعـادل او ان تدفع

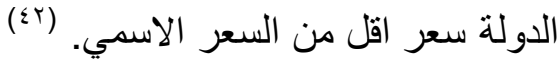

\section{الفرع الثاني / تدبير الموارد اللازهة لاستهلاك القرض العام :-}

يمكن للاولـة ان تـخلص مـن العبء المـالي للقرض بتدبير الامـوال مـن خـلال اللجوء الـى احدى

الوسائل الاتية كما يمكن الجمع بين الوسائل لاستهلاك القرض وتتمثل الطرق بالاتي:-

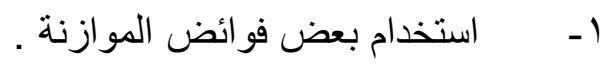

r- تخصيص بعض الاير ادات العامة مثل الضر ائب و الرسوم .

r- عقد قروض جديدة لاستهلاك قروض قديمة .ان هذا الاسلوب يكثف عن ضعف ماليـة الدولة لأنـه لا يعمل على خفض الدين العام بل يعمل على تر اكمه . ـ - اللجوء الـى الاصدار النقدي الا انه خطر لمـا يحمل من مخاطر التضخم وارتفاع الاسعار وتدهور قيمة النقود.

ــ واخيرا قد تلجأ الدولة الى بيع بعض ممتلكاتها لسداد الدين العـام وهو مـا يعرف بالخصخصـة التي

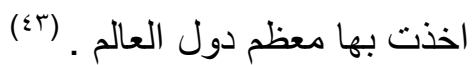
7ـ - التبديل: يقصد بتبديل القرض العام " استبدال قرض عام قديم ذي فائدة مرتفعة بقرض عام جديد ذي

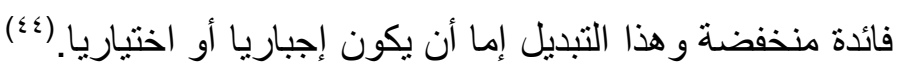
أـ التبديل الاجباري (تبديل سعر الفائدة): حيث تقوم الحكومة بتخفيض سعر الفائدة دون موافقة الدائنين وهذا التبديل يضر بالسمعة المالية للدولة ويضعف الثقة بها. بـ التبديل الاختيـاري : هنـا تعلن الدولـة رغبتها في تخفيض سـعر الفائدة ويكون لحساملي السندات حريـة الاختيار اما ان يقبلوا تخفيض الفائدة وتبديل القرض او ان يسترد قيمـة القرض الاصلي ولهذا التبديل اشكال متعددة اهمها التبديل على التكافؤ -التبديل مع دفع الفرق - و التبديل دون التكافؤ (؛؛) والتبديل يعد عملا قانونبا طالما ان شروط القرض تتضمن تخير حامل السندات بين استرداد قيمتها او استبدالها بالسندات الجديدة. (T؟) 


\section{الإلب الثالث/ انكار الدين}

يقصد بأنكار الدين توقف الدولة عن دفع ما عليها من قروض وفوائد بسبب افلاسهـا او قيام ثورة او

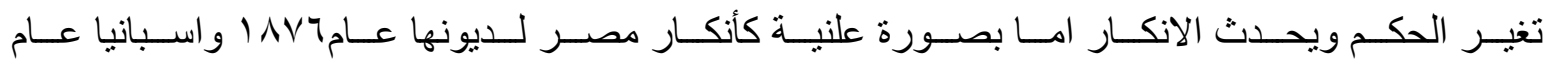

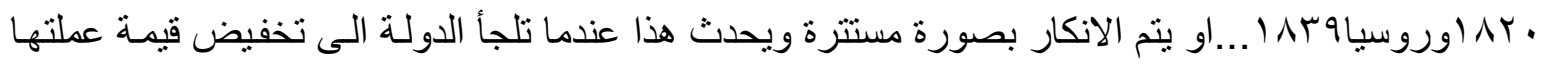
الوطنية عن طريق التوسع في الاصدار النقدي ومـا يرتبه من انهيار قيمـة العملة وتضـائل عبء القروض العامة مثال ما حدث في المانيا سنة ؟ ج ا حيث اصدرت الحكومة عملة جديدة تحل محل عملتها القديمة التي

فقدت قيمنها. (£)

ان انكـار الدين ظـاهرة تميز بها القرن التاسـع عشـر لكثرة الحروب و الثورات ولان الدولـة كانـت تقترض بشروط شديدة من حيث ارتفاع سعر الفائدة واقساط السداد وليس لتوقف الدولة او امتناعها عن دفع ديونها اي جزاء قانوني فقد تلجأ الدولة الدائنة الى الضغط السياسي او المادي على الدولة المدينة المتوقفة عن الدفع وتتم التسوية بالصلح فتتنازل الدولة الدائنة عن شيء من حقوقها مسـاعدة للدولـة المدينـة في الوفاء بباقي التزاماتها بدلا من ضياع جميع حقوقها. (^)

مما تجدر الاشارة اليه ان هذا الاسلوب اجر اء غير طبيعي وان كان يعفي الدولة من سداد دين معين الا انه يفقدها ثقة المقرضين لأجال طويلـة وتحرمها من الاكتتاب العام وتزويد الدولـة بـالإير ادات العامـة من

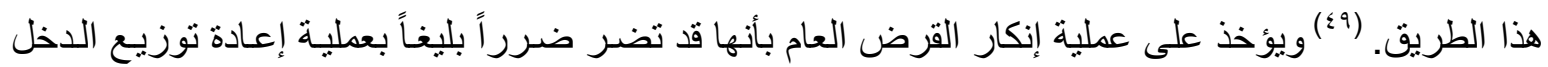
القومي لاسيما في حالة ما إذا كان المكتتبون من فئة صغار المدخرين، كذلك هنـاك عيب جوهري في إنكار القرض العـام يتمثنل في فقد التقـة بالدولـة وجهاز هـا المـالي، ممـا يهدد بعدم إقبـال الأفر اد على إقر اضـها مـرة أخرى وتبدو الخطورة أكثر وضوحاً في حالة القروض الخارجية فقد يترتب على إنكار دولة مـا لقروضها الخارجية لتعرض هذه الدولة إلى فرض عقوبات دوليه متعددة تصل إلى التدخل العسكري أحياناً. (•)

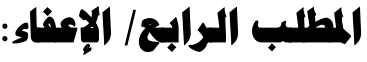

وذللك بأن يتم الاتفاق بين الدول بشكل جماعي أو انفرادي على إعفاء الدولة المدينـة من ديونها أو من

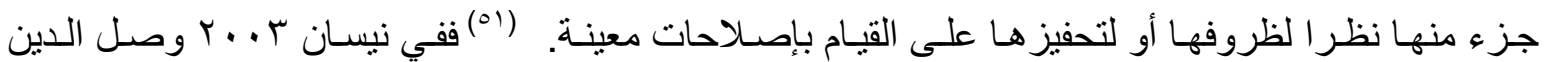
الخارجي للعر اق إلى مـا يقارب • ـ ا مليار دو لار ضمنها ديون دول الخليج العربي وبعد مفاوضـات طويلة مع صندوق النقد الدولي و نـادي بـاريس أدت إلى إطفاء أو إلغاء الـ \% ٪ ـ منها و لم يتبقى سوى ديون دول الخليج العربي.(م)، وقد يحدث ان يتنازل الدائنون عن ديونهم للاولة وذلك لإظهار مساندتهم لهاو هو مـا يحدث في الازمات والكوارث الطبيعية او في تغير نظام الحكم ....حيث يعتقد الدائنين ان تنازلهم عن القرض العام

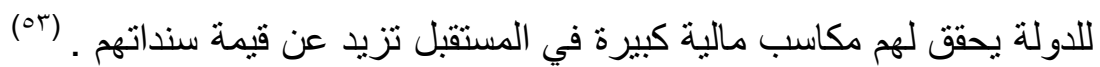

الغاتمة

بعد ان بينا اهمية عقد القرض في حياة المجتمع ونظر الكون القرض لم يعد مصدر استثنائي بل عد من مصادر الاير ادات المهمة للدولة التي يجب على الحكومة ان تستخدمه في احسن صور لكي لا يكون عبئـا 
ثقيلا على الدولة والاجيال القادمـة لذا نود ان نبين اهم النتائج و المقترحات التي من الافضل الاخذ بها عند

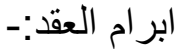

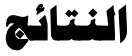

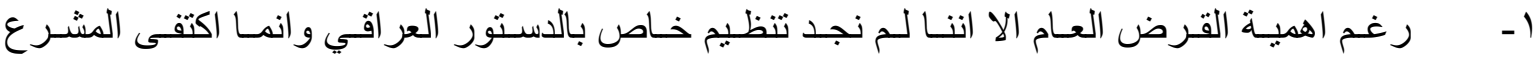
بنصوص قانون الادارة المالية والدين العام.

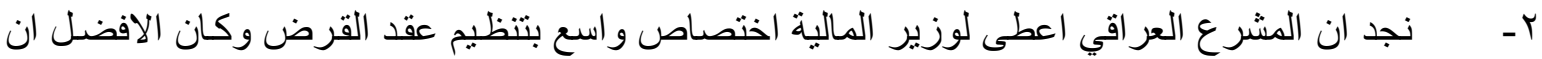
يحد من هذا الاختصاص على اعتبار ان وزير المالية من السلطة التنفيذية . ا ـ على السلطة التشريعية ان تنظم عقد القرض بقانون خاص ومستقل وو اضح اسوة بقوانين الضريبة كون القرض لا يقل اهمية عن الاير ادات الاخرى ،كما ان الدستور العر اقي قد اغفل عن تنظيمه . r- انشاء هيئة مستقلة تابعة للسلطة التشريعية(تختلف في عملها عن اللجنة المالية والاقتصـادية في البرلمـان) تولى مهمة تنظيم العقد وتحديد مبلغه و الفوائد و المدة القانونية المتفق عليها للوفاء بعقد القرض وبيان اسباب انعقاده كما تقوم الهيئة بمهمة الرقابة على ان القرض تم صرفه بصورة صحيحة وضمن الاتفاق المسبق مع الحكومة.

ب- يجب ان تكون اجازة البرلمان لعقد القرض اجـازة فعلية وقانونيـة وان تنم مناقثنة شروط القرض بصورة علنية ، لكي يكون الثعب على علم بقيمة القرض و الفوائد القانونية المترتبة عليه ...... الخ من الثروط. ع ـ انشاء محكمة تختص بالنظر بالمناز عات المتعلقة بعقد القرض العام. هـ توظيف عقد القرض للمشاريع الاقتصادية الربحية والاستثمارية الكبرى بهدف النهوض بالمجتمع.

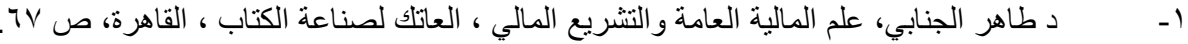

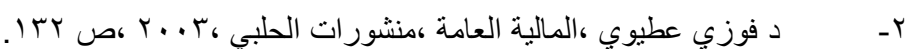

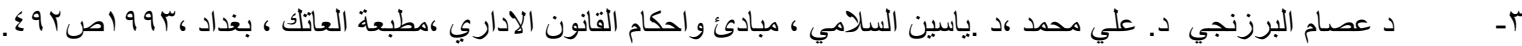

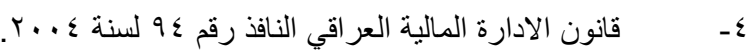

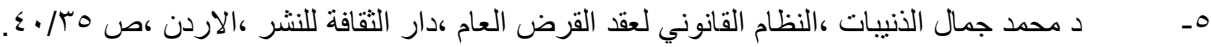

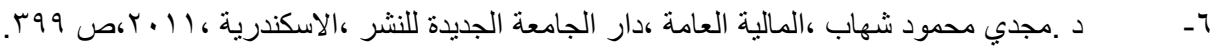

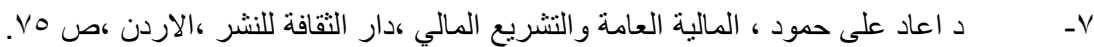

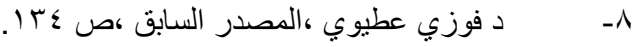

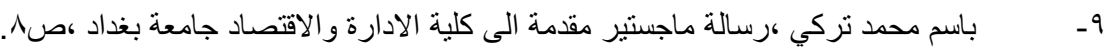

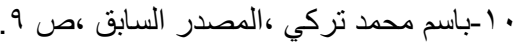
http://www.f-law.net/law/threads -- )

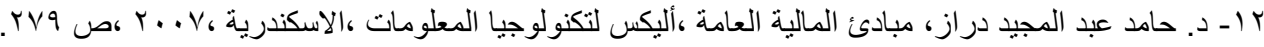
http://www.f-law.net/law/threads - I

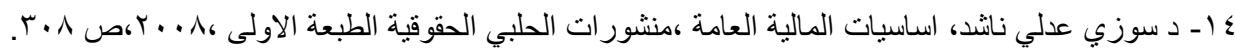

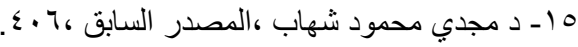

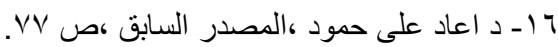

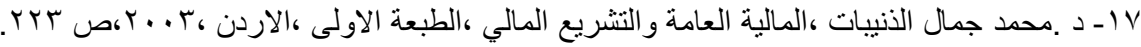




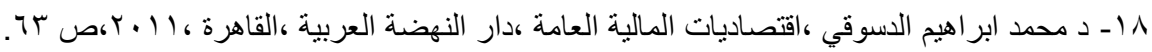

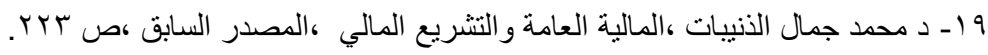

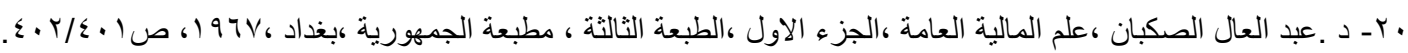

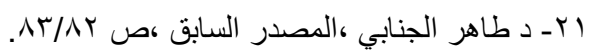

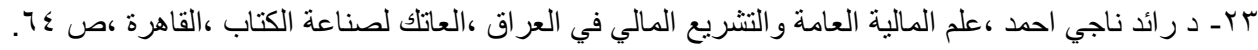

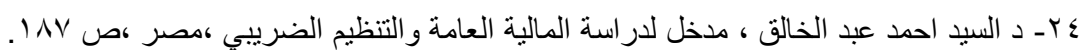

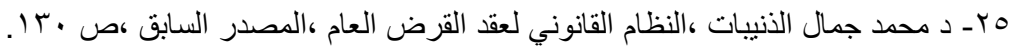

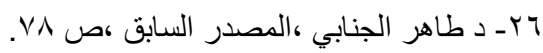

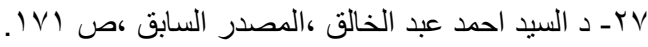

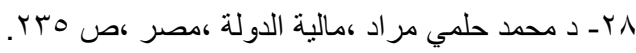

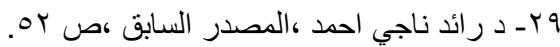

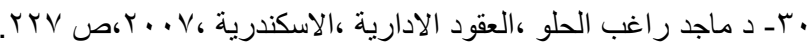

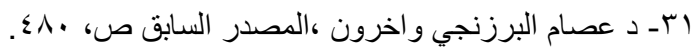
با بـ د حيدر و هاب عبود ،در اسة في الطبيعة القانونية للقروض العامة ،بحث مشور على على الأنترنت.

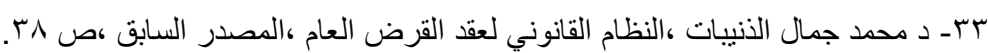

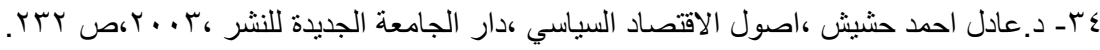

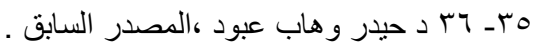

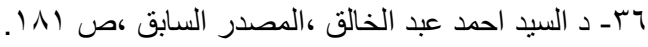
Tr

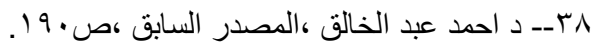

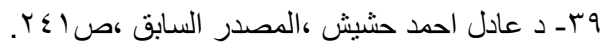

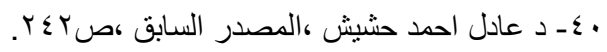

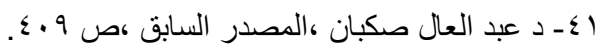

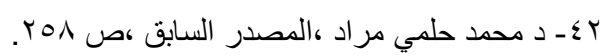

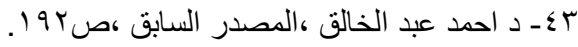
http://www.f-law.net/law/threads - $\varepsilon \varepsilon$ هـ ـ د سوزي العدلي ،المصدر السابق ،ص باسب. $5-\varepsilon \tau^{2}$

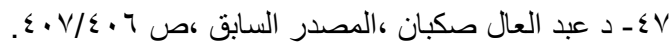

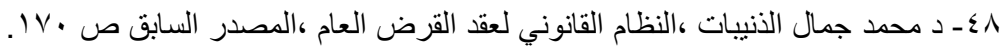

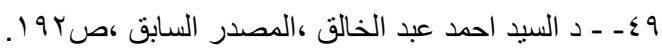

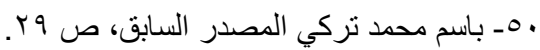

http://www.f-law.net/law/threads - 01 https://www.cbi.iq/index.php?pid=GovernmentSecurities -or

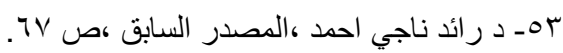


د طاهر الجنابي، علم المالية العامة والتشريع المالي ، العاتلك لصناعة الكتاب ، القاهرة.

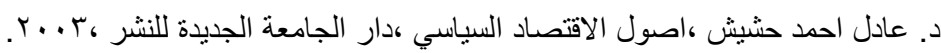

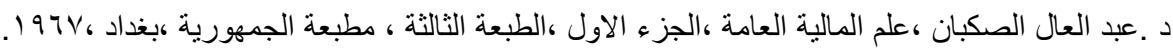

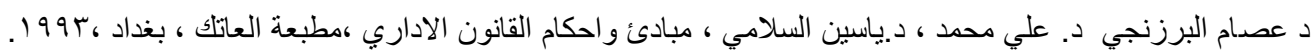

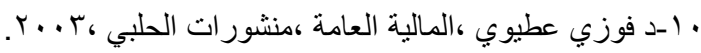

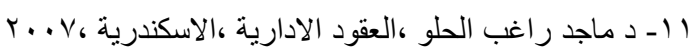

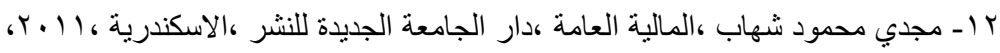

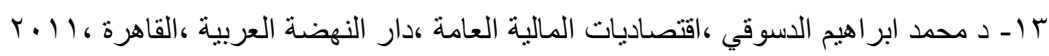

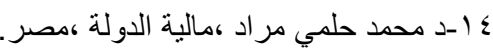

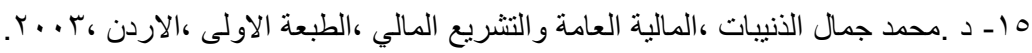
7 ا ـ د محمد جمال الذنيبات ،النظام القانوني لعقد القرض العام ،دار الثقافة للنشر ،الاردن. ثانيا/ الرسائل والبحوث والمصادر الإليكترونية. باسم محمد نركي ،رسالة ماجستير مقدمة الى كلية الادارة والاقتصاد جامعة بغداد ،لسنة V . . ب. د حيدر و هاب عبود ،در اسة في الطبيعة القانونية للقروض العامة ،بحث مشور على الأنترنت. . http://www.f-law.net/law/threads https://www.cbi.iq/index.php?pid=GovernmentSecurities ثالثار القوانين دستور جمهورية العراق النافذ لعام ه. . ب.

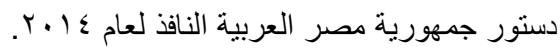

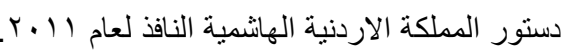

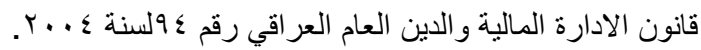

